\title{
FRP Strengthening of structures - bridging gaps in academic research and industry - 25-years' experience creating innovation
}

\author{
Björn Täljsten ${ }^{1, *}$ \\ ${ }^{1}$ Luleå University of Technology, Department of Structural Engineering, SE-971 87 Luleå, Sweden
}

\begin{abstract}
This paper presents experience how academic research and industrial needs can be bridged together, focusing on external bonding with FRP:s. The paper is based on personal experience from research at university level where the results was brought to the industry and then further developed. The work spans from theory that was incorporated in design manuals to practical instruction how to install FRP:s on site. The author discusses the research from the end of the 80ties until today and how this research successfully was implemented in the construction industry. At the end a process for innovation is presented, based on the finding from research and implementation. The overall work can be divided into five phases; research, development, demonstration, implementation and finally innovation.
\end{abstract}

\section{Introduction}

There should always be a discussion how research and industry can interact to create most usable outcome from research that will finally end up in an innovation in the Industry. All might not agree with this but for the building industry where the applied research is dominant, in opposite for example research in chemistry and physics which to a high degree can be defined as fundamental research, is it essential that research results can be implemented. The research does not need to be implemented immediately and all research might not be implemented at all but the intention should be to create and innovation. That means a system/product/service that are commonly used and are profitable. However, if research questions and long term research is to be accepted and asked for in the construction industry a close relation between the industry- and university partners is recommended. Here the phases from research to implementation and final innovation can in its simplest form be divided into; Fundamental research, Applied research, Demonstration, Implementation and Innovation. In the construction industry often the only phases that are focused is applied research and implementation. This often can lead to non-calibrated processes or other mistakes with not enough focus on the innovation phase and not enough effort put into the demonstration phase. For the construction industry the demonstration phase is essential for a long term success and a focused innovation process essential for increased revenues and profits. This paper discusses rehabilitation and strengthening of concrete structures in general and strengthening with FRP (Fibre Reinforced Polymer) materials in particular. It focuses on the process to make research successful in the industry and what needs to be considered and what gaps needs to be overcome. It also discusses the innovation process in relation to FRP strengthening of concrete structures. The paper presents mainly the work carried out at Luleå University of Technology in Sweden and is based on research and development carried out during the last $25+$ years.

\section{Rehabilitation of Concrete Structures}

As anyone knows concrete is a building material with a high compressive strength and a poor tensile strength. A structure without any form of reinforcement will crack and fail when subjected to a relatively small tensile load. The failure occurs in most cases suddenly and in a brittle manner. To increase a structure load carrying capacity and ductility it needs to be reinforced. This is mostly done by reinforcing with steel bars that are placed in the structure before the concrete is cast. Since a concrete structure usually has a very long life the demands on the structure will normally change over time. The structures may have to carry larger future loads or meet new standards. In extreme cases, a structure may need to be repaired due to accidents. Another more reason includes errors made during the design or construction phase so that the structure needs to be strengthened before it can be used. It should also be remembered that over the past decade, the issue of deteriorating infrastructure has become a topic of critical importance in Europe, and to an equal extent in the United States and Japan. For example, the deterioration of decks, superstructure elements and columns of bridges can be traced to reasons ranging from ageing and environmentally 
induced degradation to poor initial construction and lack of maintenance. As an overall result, a significant portion of our infrastructure is currently either structurally or functionally deficient. Beyond the costs and visible consequences associated with continuous retrofit and repair of such structural components are the real consequences related to losses in production and overall economies related to time and resources caused by delays and detours. As we move into the twenty-first century, the renewal of our lifelines becomes a critical issue. To keep a structure at the same performance level it needs to be maintained at predestined time intervals. If lack of maintenance has lowered the performance level of the structure, need for repair up to the original performance level may be required. In cases when higher performance levels are needed, upgrading can be necessary. Performance level means load carrying capacity, durability, function or aesthetic appearance. Upgrading refers to strengthening, improved durability, and change of function all related to safety. In the last three decades the development of the FRP external plate bonding technique has been shown to be applicable to many existing strengthening problems in the construction industry. This technique may be defined as one in which composite sheets, plates or NSM (near surface mounted) reinforcement of relatively small thickness are bonded with a two component epoxy adhesive to, in most cases, the surface of a concrete structure to improve its structural behaviour and strength. The sheets or plates do not require much space and give a composite action between the adherents. The old structure and the new bonded-on material create a new structural element that has a higher strength and stiffness than the original. The basic ideas related to the use of FRPs (Fibre Reinforced Polymers) for structural strengthening, along with examples of application, have been presented by [1]. The most common way to strengthen structures has been for flexural strengthening and confinement but also shear strengthening is quite common.

\section{Academic Research}

\subsection{General}

The academic building research in Sweden, in general, has to a large extent been carried out with success and with a close relation to the industry - even though the universities most commonly put up the research agenda. This collaboration has been predominant during the last two decades and a large amount of the research is carried out by $\mathrm{PhD}$ students taking part in research groups in collaboration with and supervised by seniors and professors.

\subsection{Long term perspective}

To my point of view research must have a long term perspective, where the researcher will have time study and reflect over hypotheses and stated research questions. On the other hand, if the research is to be successful from an industrial view a balance between short and long term perspectives must be respected and accepted and the need from society must also be considered.

In the end of the 80-ties we had several brainstorming sessions at the department where we discussed and reflected over our future research. These sessions lead to several good and fruitful research ideas, where assessment of existing civil structures was one. It was quite clear that everything what have been built also needed to be taken care of. At that time quite large investments were put on new built in Sweden so neither the industry and the road- or the railroad authorities was particular keen in investing money in research towards assessment and rehabilitation. So even though we had a long term perspective with our research - not many of our funders shared our belief in future research in this direction. Despite this, with limited resources we started our research. And looking back, this was a good decision considering how far we have reached since then.

\subsection{External strengthening of structures}

\subsubsection{Steel plates}

The research with external strengthening started in Sweden in the end of the 80-ties where the Swedish Road Authorities (Today "The Swedish Transport Administration") were facing new load demands from the European Union. Here great focus was placed in methods that could increase the load carrying capacity of existing concrete bridges. From literature it was found that external steel plates had been used quite extensively around the world during the 70-ties [2], this was also the foremost method they wanted to investigate. From 1988 until the beginning of the 90-ties our research was entirely on external steel plate bonding, which then also included full scale testing. During the literature study it was found that extensive research had been carried out in this field during the 70-ties and 80-ties and that many of the problems studied today in relation to external FRP bonding was already mentioned and discussed then, in particular end-peeling and anchorage lengths [3]. The strengthening method with external steel plates worked excellently and was brought into the Swedish bridge code in 1989. In Fig. 1 a photo of the full-scale test is shown.

Even though the strengthening method technically worked as intended the method did not show any real success on the market and could not be considered as an innovation. There were several reasons for this and the limitation in transportation length, the heavy weight of the steel plates, the need for joining plates and corrosion are some of the major drawbacks that was brought up.

In 1989 a study visit was made to EMPA in Switzerland. Here research with carbon fibre reinforced polymer (CFRP) laminates that was ongoing parallel with tests with steel plate bonding. I thought the tests with CFRP was very interesting, but had no expertise at all in composites. Back at the University I started investigations regarding FRP, but no one in the 
construction industry in my vicinity thought this was a way forward for external strengthening - steel, concrete and timber are what you use in the building industry for construction. Nevertheless, I did manufacture some composite plates myself - one of my mistakes - with glass fibres and epoxy. Not obtaining very high fibre content, maybe $30 \%$ at most. Bonded these plates to concrete prisms and did some lap tests - and by no surprise - with very poor results as a consequence. And, which maybe was even a bigger mistake, I then went back carrying out additional tests with steel plates. The research was at this moment focused to understand debonding problems related to end-peeling and anchorage, where the outcome later on was in of the first closed analytical models for the end-peeling [4].

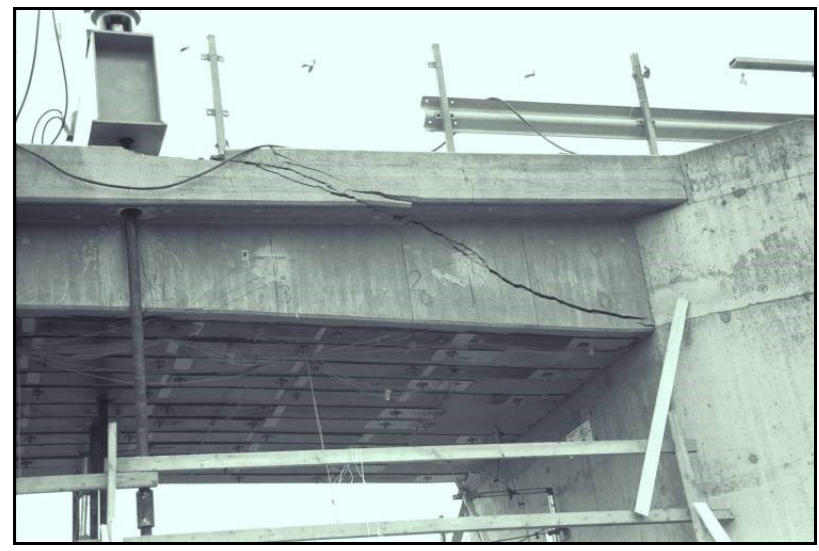

Fig. 1. Full scale test of an externally steel plate strengthened concrete bridge, (Täljsten, 1989)

\subsubsection{Fibre Reinforced Polymers}

In the beginning of the 90 -ties our research now shifted towards FRP and the use in external strengthening. The research was very much based on our earlier research in steel plated bonding and was not directly driven by industry needs, more then by the interest of the university and the researchers (me). One of the first tests carried was concrete beams strengthen by CFRP laminates for flexure. Here the end-peeling effect was primary investigated and laboratory tests compared with derived theory from [4]. Other tests were parallel carried out on concrete prisms to investigate the bond length. During the following years research to study the effect of torsion, shear strengthening and strengthening during traffic loading, fatigue, cold climate, strengthening of openings have also been carried out as well as strengthening with NSM (Near Surface Mounted) reinforcement but also the use of prestressing and FRCM (Fibre Reinforced Cementitious Mortars) has been researched.

\subsection{Outcome from research}

\subsubsection{General}

To present all the results and findings in our research during the last 25-30 years are not practicable and is not either the intention of this paper. I will try to keep the presentation of our work very concise. In general the research can be divided into strengthening for flexure, strengthening for shear/torsion, fatigue and FRCM strengthening methods. We have carried out analytical and numerical studies as well as a large amount of laboratory work and several full scale test. In addition to this we have so far used the methods in more than 500 different projects over the years only in Sweden. In the section below it's only referred to our work at Luleå University of Technology, even though the author is aware of that many others have done similar research and sometimes with more successful results.

\subsubsection{Strengthening for flexure}

End peeling, anchor length and IC debonding

Peeling failure in EBR (externally bonded reinforcement) is one of the factors that consider to limit the full utilisation of an external FRP strengthening system. Most commonly is that a crack in the concrete structure develops and propagates towards one of the plate ends. An end peeling crack occur at the cut off end of a plate and a IC (intermediate crack) is induced somewhere between the plate ends, often where the maximum bending moment and shear force superpose each other. The phenomenon of debonding issues is not new and has been studied since long, se for example Volkersen, 1938, [5]. For external plate debonding early research was presented in [6], [7] and [8]. No one of these models presented a closed form solution. Research at Luleå University of Technology lead to the first presented closed solution to the end peeling problem and was first presented in 1994, [4] and published in a paper in 1997, [9]. Since then many updated models exists to predict the end peeling behaviour. A very good model for IC-debonding has been presented in [10] and in [11] a practical design model for IC-debonding is put forward.

\section{Strengthening during moving load}

Normally owners of structures want to continue their activity or service during strengthening, but it has been questioned how this will affect the final strengthening result. At Luleå University of Technology, Department of Structural Engineering laboratory tests have been carried out of concrete beams strengthening in flexure and subjected to a cyclic load during setting of the adhesive. The beams where then loaded up to failure. The results show that strengthening with CFRP systems, both laminates and NSM, are possible even if load act on the structure during the strengthening phase. No significant effect of the cyclic load could be detected in comparison with reference beams without any cyclic load during adhesive setting. More detailed information can be read in [12].

\section{NSM}

Since 1996 several laboratory tests with NSM in flexure have been carried out at Luleå University of Technology, Division of Structural Engineering. In the test presented 
epoxy bonded and grout bonded rectangular NSM rods were used to strengthen reinforced concrete beams. The beams were tested in four point bending, a more detailed presentation of the tests can be found in [13], [14]. In the static four point bending test, four rectangular concrete beams were manufactured, three were strengthened and one served as a reference beam. The geometry and loading conditions and the results from testing are shown in Fig. 2.
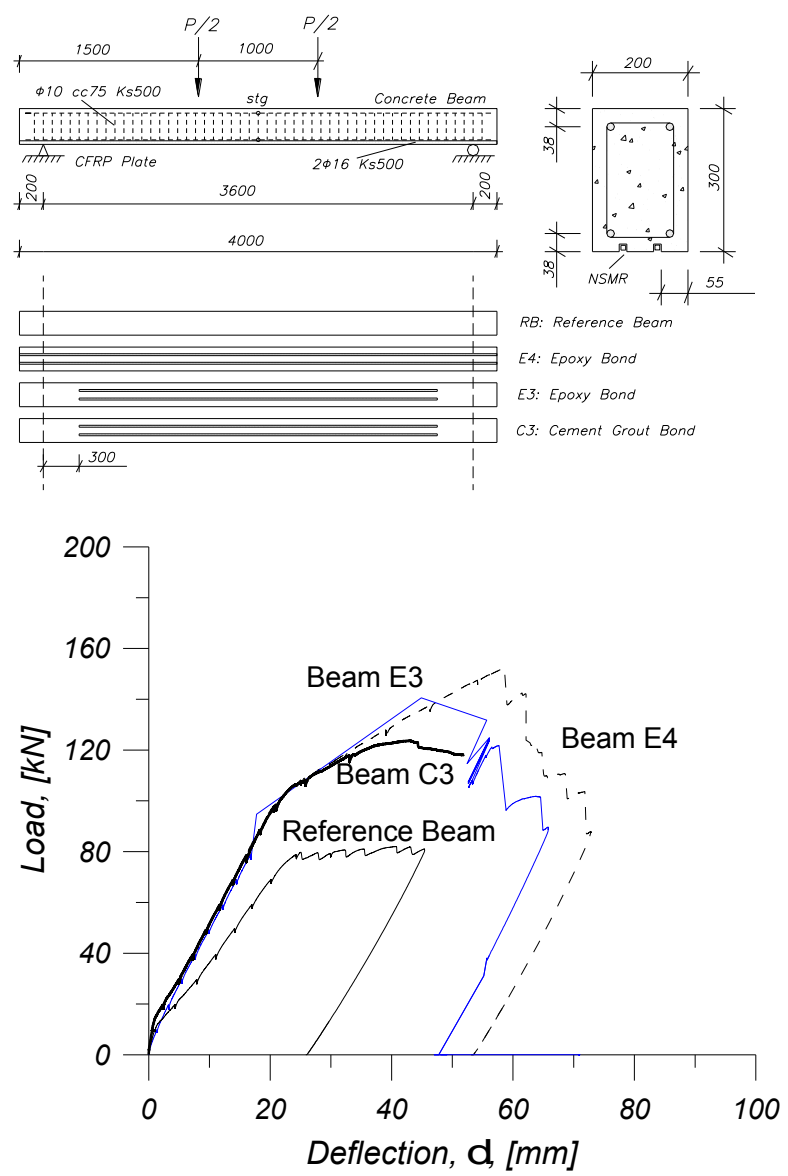

Fig. 2. NSM beams tested in flexure

It can be noticed that Beam E4, bonded outside the supports, showed the best failure envelope, where failure was by rupture of the rod. Beam E3 and Beam C3 follow each other up to the level where an anchorage failure arises in the cement grout for Beam C3. In Beam C3 cracks parallel to the laminates appeared and while the load increased the mortar started to fall down from the beam. Beam E3 showed a more ductile behaviour but also suffered an anchorage failure.

\section{Cold temperature}

Most common has been to test different strengthening configurations in ambient temperature. However, the environment surrounding us varies considerable and for the northern hemisphere it is not unusual with temperatures down to $-30{ }^{\circ} \mathrm{C}$ or below in the winter time. Studies Carried out by Clarin [15] in 2002 that beams strengthening in flexure and loaded to failure in $28^{\circ} \mathrm{C}$ showed no negative influence of low temperature in comparison with similar beams tested in room temperature.

\section{Prestressing}

There are four main advantages to prestress the CFRP strengthening material; 1) Higher utilization level of the strengthening material, 2) Decreased crack size and mean crack distance, 3) Unloading of the steel reinforcement and 4) Higher steel yielding loads

In the service limit state decreased crack size will be very beneficial for a concrete structure. Smaller crack sizes and distance between the cracks will most likely increase the durability as well as the stiffness of the structure. The largest advantage with prestressing the strengthening material is probably the increased steelyielding load. Studies has shown almost $50 \%$ increase in steel yielding compared to unstrengthen structures and up to $25 \%$ compared to not prestressed strengthened structures [16]. Fig. 3 shows the typical behaviour of beams loaded with four-point bending. The values are from the study by Nordin et. al., [16]. Three important stages are shown; concrete cracking, steel yielding and the ultimate load at failure. A non-prestressed strengthened beam has about the same cracking load as a non-strengthened beam, where the beam with prestressed strengthened FRP has approximately twice the cracking load. For steel yielding the strengthening effect is almost double for prestressed strengthening compared to no prestress, this effect is of course also dependent on the level of prestress applied. At Luleå University of Technology we have also developed systems for prestressing using external tendons. The effort was here to develop a anchor system that could transfer the force into the concrete structure without anchor rupture. This was successful and has been presented in [17] and [18].

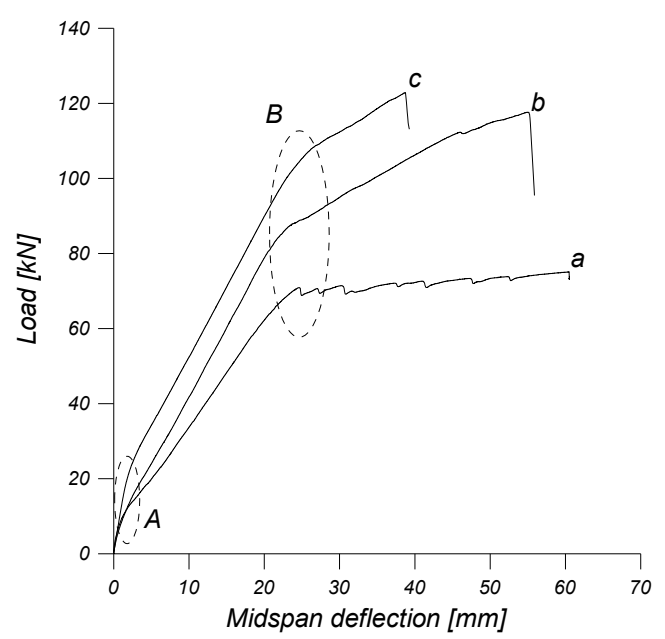

Fig. 3. Prestressed NSM

Strengthening of openings

There exists a need to introduce sectional openings in floor as well as in wall structures. The structural effect of small openings is often not considered due to the ability of the structure to redistribute stresses. However, for larger openings the static system may be altered when considerable amounts of concrete and reinforcing steel have to be removed. This leads to a decreased ability of 
the structure to resist the imposed loads and the structure needs therefore to be strengthened. At Luleå University of Technology we have researched strengthening of rectangular openings in slabs, [19], [20] and walls [21], [22] both small and larger openings have been investigated. As long as the opening is small, strengthening has a minor effect and it is most important to stop cracking in the corners of the opening, which can be done by placing CFP sheets perpendicular to the corner. For larger openings, particular in walls often a combination of strengthening to prevent shear and bending is needed. Here we have investigated the use of CFRP sheets and NSM bars both in laboratory environment and in field applications. However, there is still research needed when it comes to strengthening of walls [23]. In Figure 4 preparation before making an opening is shown.

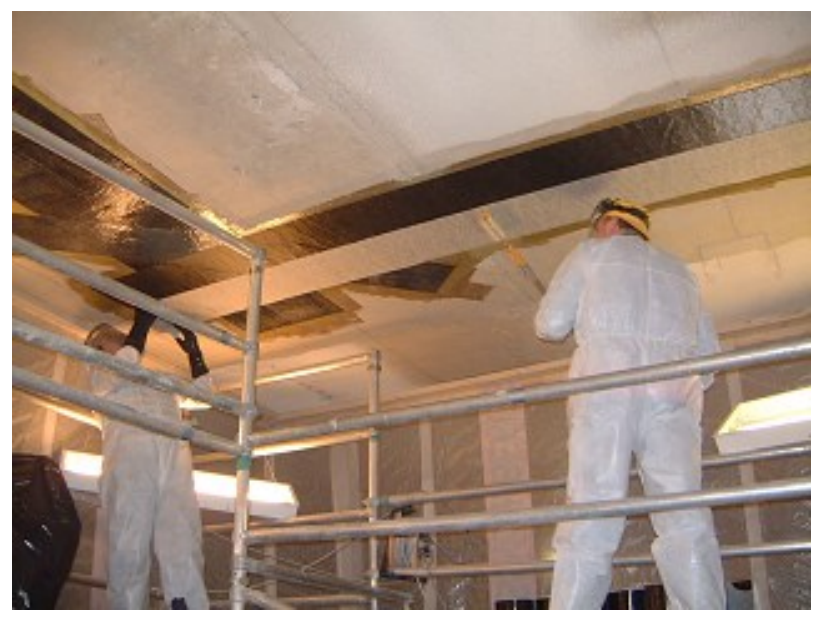

Fig. 4 Strengthening with CFRP sheets before making an opening for a ventilation duct in an existing slab due to changed functional requirements. (Photo Björn Täljsten, 2000).

\section{Strengthening for fatigue}

The behavior of reinforced concrete beams strengthened with CFRP EBR plates and NSM bars under monotonic and fatigue loading by four-point bending has been investigated, [24], [25] Strengthening materials with two different Young's modulus values (150 and $200 \mathrm{GPa})$ were examined, and the effect of pre-existing cracks in the beams before the application of the strengthening material was investigated. The results obtained indicate that the fatigue life of concrete beams could be extended tremendously compared to non-strengthen beams. Failure was initiated by steel bar rupture. The dominant failure mode in all beams that failed during fatigue loading involved intermediate debonding at the position where the steel bars ruptured. In general, the stiffness of the beams declined gradually after the first rupture, so their failure was ductile. In general, the EBR plated beams showed a better fatigue behaviour compared to the NSM strengthen beams and the fatigue life was prolonged most with the lowest Young's modulus. The reason for this is most likely that the EBR plates was placed on the surface of the beams keeping the cracks together to a higher extent and that the CFRP with the lower modulus had a longer elongation to failure.

\subsubsection{Strengthening for shear}

At Luleå University of Technology, extensive research regarding of concrete beams strengthen for shear with FRP has been carried out. Research started early with external strengthening with steel plates, [4] and have since then been developed gradually. A paper presented by Carolin and Täljsten [26], [27] in 2005 where the differences between steel and FRP strengthen beams in shear was clearly stated. More than 100 beams have been strengthened and evaluated over the years at Luleå University of Technology. From this research it is by no doubts clear that concrete beams can be strengthen in shear with both steel plates- and FRP systems. Since late 1990-ties and early 2000-ties different shear models have been launched and many (different) models has also been incorporated in design guidelines and codes, for example [28], [29], [30] and [31]. It could however be questioned how accurate these models describe the load carrying capacity of shear strengthened FRP beams. Some of the models are more accurate than others but tend then to be very complicated, others might be to much simplified. A very interesting study by Sas et. al. in 2009, [32] and by Sas [33] where the most common shear models are questioned and compared with an extensive database where more than 250 strengthened beams with different configurations stressed the complicated behaviour of FRP strengthen beams in shear. No model could completely predict the failure accurately. A design model shall not be too complicated and at the same time being able to describe the physical behaviour. A modified model has been presented in [34]. This model is not either a perfect one, and might also be characterised as an engineering model, but with limitations regarding anchor lengths and that only Uwrapped and completely wrapped configurations are allowed the model is considering giving results on the safe side.

\subsubsection{FRCM strengthening}

Even though epoxy is the dominating bonding agent for FRP strengthening, it may also create problems in the working environment, needs a minimum application temperature and creates diffusion-closed surfaces. These drawbacks can be overcome if the epoxy can be replaced with a cementitious bonding agent. Epoxy can successfully be replaced with a mineral (cement) based bonding agent for retrofitting. Tests show that very good composite action can be achieved and that only minor changes in the design procedure needs to be taken, 36 . The structures can be strengthened for flexure as well as for shear. In our research that slabs strengthened with CFRP grids and bonded to concrete with a cementitious bonding agent are comparable to a slab strengthened with epoxy bonded carbon fiber fabrics and a slab with increased steel reinforcement, [36] [37]. 
The FRCM system involves using a grid of fibre composite and the assembly of the strengthening system is fairly uncomplicated. The surface of the base concrete in need of strengthening is first prepared by removing the cement laitance with a surface roughening method, e.g. sand blasting or water jetting. The strengthening system is applied in four consecutive steps. Firstly, a surface primer is applied on the roughened base concrete surface to reduce moisture transport from the polymer modified mortar to the fairly dry base concrete. Secondly, one layer of a cementitious bonding agent is applied on the primed base concrete surface. Thirdly, the FRP is applied on the first mortar layer (in the present thesis a CFRP grid is used). Finally, a second layer of mortar is applied on top of the first layer and the FRP, in Fig. 5 the FRCM System used for shear strengthening is shown schematically [38]. Tests presented in [38] shows that the strengthening effect in shear correspond well to similar concrete beams strengthened by epoxy bonded systems designed for the same ultimate failure load. The system has been further developed, [39] and also used for strengthening of openings in walls, see Figure 6.

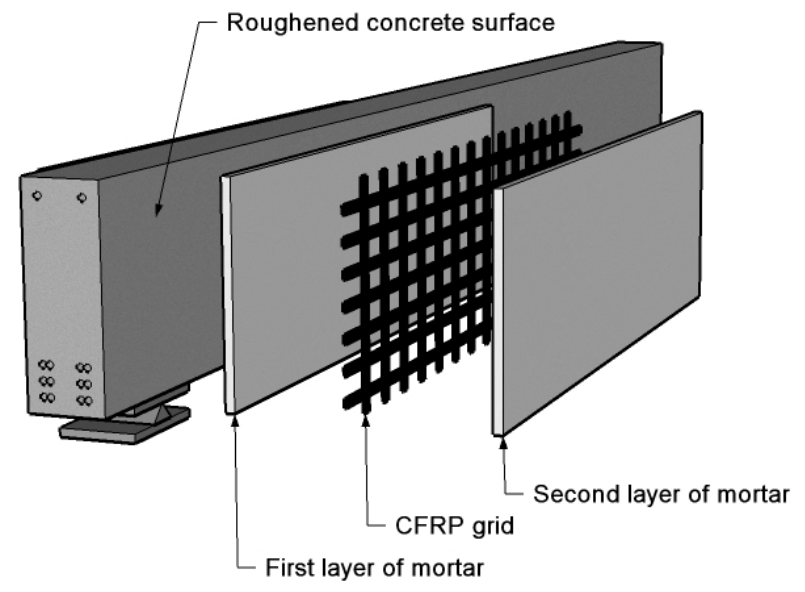

Fig. 5. MBC shear strengthening of an concrete beam, 38

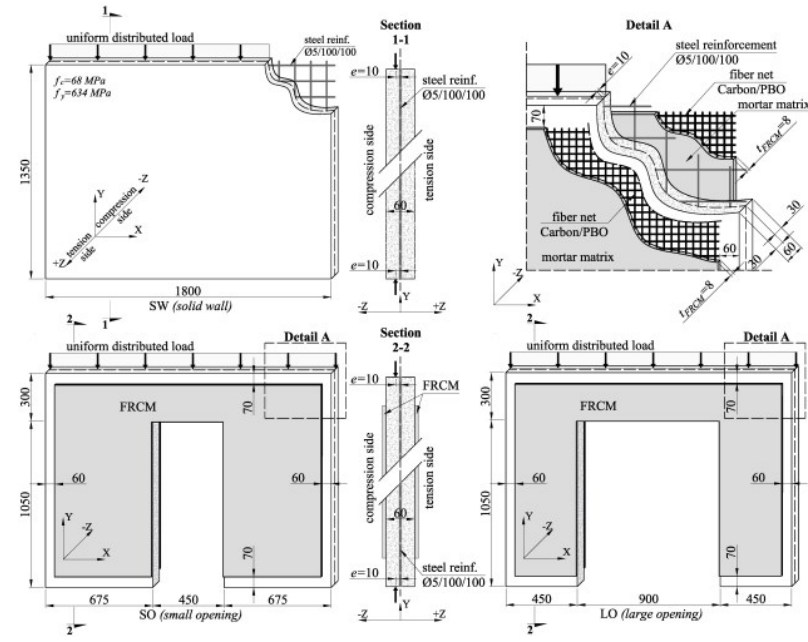

Fig. 6 Testing of FRCM strengthened openings in scale-up walls, [39]

\section{Industrial Needs}

\subsection{General}

R\&D (Research and Development) is often not a prioritised part of the business in the building industry. This yields in general for the construction companies as well for consultants and architects, but normally not for the material suppliers. To understand how the industrial needs are created we have to understand the very complex industry and how building objects are handled and carried out. Patents in the building industry are often of low value, at least patents related to design or execution. The construction projects are carried out in project form and in the very large projects a turnover of 2 billion Euros or more is not uncommon. A project can often be seen as an own entity. And often when a project is started all technical challenges are not solved, but are expected to be solved during the project different phases, which can be defined as project development. Despite the low direct investments in R\&D the industry invests in project development but have a tendency to "invent the wheel" in every project. This is why it is important for the industry to work closely with academia to put the development into long term perspective. Looking into the next 20-50 years the society stands in front om extreme big challenges related to:

- Energy supply

- Environmental pollution

- Fast increase of mega cities

- Increased travelling and transportation

- Maintenance of the already built society, buildings as well as civil structures.

And in all these areas the building industry will be deeply engaged. That means that the construction industry needs to put on a broader view on R\&D and the need of long term engagements.

\subsection{Long term perspective}

Development projects in the construction industry are often carried out with a short term perspective where a specific topic needs to be solved. This is dominantly carried out in an ongoing construction project, where the main focus is not on the development project but on the construction project itself. However, if the industry is to follow the future demands on the society a long term perspective regarding research, development, demonstration, implementation and innovation is needed. However, the challenges are too big to be able to be solved or financed by the construction industry alone. The industry as it is structured cannot bear this cost itself which is the case in many other industries, e.g. car, smart phone manufacturers, recreational industry etc. where the costs can be transferred to the customer in a more visible and clear way. 
It is my opinion that the government have to invest more $R \& D$ resources into the building industry together with the construction companies, in particular related to long term initiatives. Here long term collaboration between universities and the industry can bridge a part of that gap.

\section{Bridging Academia and Industry together}

\subsection{General}

There are many benefits if academia and the construction industry would work closer together. For example, the long term perspective in academia could balance the shorter term perspective from industry - both are needed. To describe how this should be done in detail is not doable in this paper however, at least the following pit-falls should be avoided:

- To short perspective; Try to focus on long term goals with innovations in view and not only the outcome in the specific construction project

- Involvement of the industry; Academia should involve the industry early in a research project where the final goal is implementation and innovation

- Power of endurance and financing; The government and government authorities must take a larger responsibility for their own assets, people and investments. This means that they have to be involved in the research process.

- Mutual understanding; Lack of industrial understanding in academia and lack of academic understanding in industry. This is a risk if no natural interfaces exist - which often is the case. A bigger interaction between academia and industry is needed. For example, people working both at universities and in industry.

\subsection{Experience}

From my experience there are a number of key objectives that must be fulfilled if an industry collaboration should work. Firstly; a common interest, secondly; financing and thirdly; people that understands the similarities and differences between academia and industry. It is also of utmost importance that the research project has a "client" and that feedback is continually given. For the building industry it is no drawback if there will be a possibility to implement the outcome from the project when finished and the same yields, from my point of view, for academia. To see the implementation of your research is a great reward for the researcher.

\section{Example of Successful Projects}

\subsection{General}

A successful project is here defined as a project where the findings from applied research (development) project in process/products or services are used in practice showing improved productivity (time, cost) or/and prolonged life or/and improved safety (work health) compared to traditional process/products or services. And if this can be repeated over time at many different projects an innovation is created.

In Sweden we have carried out a number of successful FRP strengthening projects where we have had a collaboration between industry and academia and also the Swedish Transport Administration, and where the final result can be considered as an innovation. Here only two of the projects are briefly presented.

\subsection{Flexural strengthening of a railway bridge}

Due to demands on higher axel loads the Swedish Rail Administration decided to strengthen the motor car traffic underpass at Kallkällan near Luleå town. Calculations with the higher axle load had shown that the bridge mainly needed strengthening of the slab in the cross directions between the beams. It was decided that CFRP sheets should be used for strengthening. The carbon fibre composite system used was Sto FRP Sheets S300 C300. A hand-lay up system with a standard fibre, $\mathrm{E}_{\mathrm{f}}=234 \mathrm{GPa}$ and $\varepsilon_{\mathrm{f}}=1.7 \%$. After strengthening, applied on the bridge, the fibre ratio per weight is $35 \%$ from tests. A total of 3200 meter of carbon fibre sheets with the width of $300 \mathrm{~mm}$ and a thickness of $0.34 \mathrm{~mm}$ (two layers) up to $0.51 \mathrm{~mm}$ (six layers) was applied to the bottom face of the bridge. The bridge was proof loaded and strains and deformations were measured both before and after strengthening. Short-term measurements from the test program showed that the bridge stiffness increased by approximately $17 \%$, [40] and [41]. This was the first railway bridge where external strengthening with CFRP was introduced in Sweden. The bridge where strengthen in 1999.

This was a typical project where success would not have been possible without interaction between academia and industry, in fact also the rail authority played a very important role in the project. In Sweden at this moment the strengthening technique was consider novel and had not been used for strengthening of railway bridges. A project team was established with people from academia (Luleå University of Technology), from industry (the contractor Skanska) and the Swedish rail authorities. Since no design guidelines existed at the time for strengthening it was a demand from the rail authorities that the university developed guidelines parallel with design of the strengthening.

The industry partner had carried out several strengthening projects with the CFRP technique and contributed with practical advises, and also carried out the strengthening work. The rail authority supervised and inspected the strengthening work.

\subsection{NSM flexural strengthening of a concrete trough bridge loaded to failure}

The Örnsköldsvik bridge was tested to failure in July 2006 to demonstrate and test new and refined methods developed in the European funded research project Sustainable Bridges (www.sustainablebridges.net) 
project regarding procedures for condition assessment and inspection, load carrying capacity, monitoring and strengthening of railway bridges. The bridge was originally designed for an axle load of $250 \mathrm{kN}$. Maximum design bending moments and shear forces according to the original calculations from 1954 gave a maximum shear force of 2,3 MN whereof 0.7 MN from dead load. The maximum mid span moment is $\mathrm{M}=3.6$ $\mathrm{MNm}$, whereof $0.8 \mathrm{MNm}$ from dead load. The bridge was tested with a vertical point load $\mathrm{P}$ in the mid span. This loading could from the calculations lead to a combined bending and shear failure which is interesting to evaluate and compare with code predictions and with more refined models see e. g. Enochsson et al [42] and Puurula [43]. In order to prevent a traditional bending failure, the bridge slab was strengthened rectangular Near Surface Mounted (NSM) bars of CFRP which then were mounted by bonding in sawed out groves in the slab, see Täljsten [44]. The bridge was loaded during three occasions, two times before it was strengthened and then at the failure test of the strengthened bridge. The load was applied by placing a beam reaching over the bridge deck which was fastened by cables anchored into the bedrock some 6 metres below the ground surface. Two 1000 ton hydraulic jacks provided the force. During the first loading occasion, the through slab was loaded onto the ballast to check the distribution of loads through the ballast and the load-carrying capacity of the slab. During the second and third loading occasions, the two main beams were tested. In the final test it was possible to load the bridge to a shear failure with 11.2 MN which is considerably more than what it was designed for. The strengthening system provided $30 \%$ of the resistant force and functioned well up to failure which was initiated by combined yielding in a steel stirrup and anchorage failure of the NSM system. The monitoring system was extensive and included strain gauges, LVDT.s, fiber optic and lasers. The provided a large amount of data and was very useful in evaluating the bridge together with non-linear FE.

This was a unique project since it was possible to load the bridge to failure. Without previously carried out research and a close collaboration both with the rail authorities and the applicators in the industry - the project would have been impossible to carry out.

\section{Discussions and Conclusions}

The experience from working 25+ years in both academia and industry with both applied research, demonstration projects, implementation and during the last 5 years with innovations has been very valuable and both beneficial for the universities and the companies involved. Often the aims with the research are different, both in expected outcome, time frame and cost. For example, the foremost importance for industry is to obtain return on the investments and if possible gains over competitors. Other important factors for industry may be improved existing processes related to cost savings. This should preferable also be carried out within a short timeframe - deadlines are essential. At academia often the research is carried out with longer time frames in mind, preferable if the finished project could be continued, extended or lead to new research. Return on investments is commonly not related to money, more to possibility to publish the work, number of $\mathrm{PhD}$ students examined or in best cases new findings that will put the researcher on the map or in front of his peers. Preferable the research related issues should also be possible to be used in teaching for undergraduates. Beneficial would be if a project could be defined that both meet the demands from academia and industry. This is often the case if a detailed description is put together from the beginning and if there is a balance between short term goals and long term achievements. This requires of course that also the form for financing is fulfilled. It is also a very big difference if the project is carried out by seniors or $\mathrm{PhD}$ students. For $\mathrm{PhD}$ students the time frame needs to be longer and the outcome from the research is more uncertain. In both cases it is however very important that the industry partner(s) are engaged in the project.

In this paper it has been shown that close contact with academia and industry give a fast(quite) input from research to implementation where demonstration projects are essential. Early involvement from industry speed up the implementation process, give the research focus and minimise practical problems. At the same time with industry focus the research questions may be easier to define. A risk is that the research might be too streamlined and that industry interest outweighs the need and interest from academia. On the other hand, without involvement from the industry there is a larger risk that the research will not be used as intended or that the process for implementation will be prolonged or not happen at all. What we still are missing is structured processes to create innovations in the construction Industry - at least in Sweden.

There are many people and organisations that should and that I would like to thank for the work carried out during the last 25+ years, to many to mention all here. However, I would not have created much without Luleå university and Skanska $\mathrm{AB}$, and among the many financiers I would very much like to thank SBUF (The development fund of the Swedish Construction Industry), but also the Swedish Transport Administration. In particular, I am very grateful to my previous supervisor and professor emeritus Lennart Elfgren who always had a way of supporting and encouraging me during my research.

\section{References}

1. T.C. Triantafillou, "Shear Strengthening of Reinforced Concrete Beams Using Epoxy- Bonded FRP Composites," ACI Structural Journal, Vol. 95, No. 2, March-April, 1998, pp 107-115.

2. R. L'Hermite et. J. Bresson "Beton armé dármatures collées", Colloque RILEM sur "Les résines de synthése dans la construction, Paris Ed. Eyrolles 1971, pp. 175-203.

3. T.M. Roberts, "Shear and Normal Stresses in Adhesive Joints", Jounal of Engineering Mechanics, Vol. 115, No. 11, November 1989, pp. 2460-2476. 
4. B. Täljsten, "PLATE BONDING - Strengthening of Existing Concrete Structures with Epoxy Bonded Plates of Steel or Fibre Reinforced Plastics", Doctoral Thesis - Division of Structural Engineering, Luleå University of Technology, 1994:152D, ISSN 0348-8373, 1994, p 289.

5. O. Volkersen, 1938, "Die Nietkraftverkteilung in zugbeanspruchten nietverbindungen mit konstanten lachenquerscnitten, Luftfahrtforschung, 15, 1938, pp 41-47.

6. H.H. Kazemi, 1989, "Behavior of reinforced concrete beams with externally attached steel plates, PhD Thesis, Department of Civil and Structural Engineering, University College, Cardiff, 1987, p 143.

7. T.M. Roberts, 1989, "Shear and Normal Stresses in Adhesive Joints, Journal of Engineering Mechanics, Vol. 115, No 11, Nov. 1989, pp 21-27

8. O. Vilney, 1988, "The analysis of reinforced concrete beams strengthened by epoxy bonded steel plates", The international journal of Cement Composites and Lightweight Concrete, Vol. 10, No. 2, My 1988, pp 73-78

9. B. Täljsten, 1997, "Strengthening of Beams by Plate Bonding", Journal of Materials in Civil Engineering, November 1997, pp. 206-212.

10. J. Yao, J.G. Teng and J.F. Chen, 2005, "Experimental study on FRP-to-concrete bonded joints", Composites: Part B: Engineering, 36, Elsevier, pp 99-113.

11. ACI, 2017, "Guide for the design and construction of externally bonded FRP systems for strengthening concrete structures, ACI 440.R2-17, American Institute, Farminton Hills, Michigan.

12. A. Carolin, B. Täljsten, and A. Hejll, 2005: "Concrete Beams Exposed to Live Loading during Carbon Fiber Reinforced Polymer Strengthening". Journal of Composites for Construction, Volume 9, Issue 2, pp. 178

13. B. Täljsten, and A. Carolin,, 2001: "CFRP Strengthening. Concrete Beams Strengthened with Near Surface Mounted CFRP Laminates" Fibre reinforced plastics for reinforced concrete structures, FRPRCS-5, Cambridge (Edited by Chris Burgoyne), pp 107-116

14. A. Carolin, H.Nordin and B. Täljsten, 2001: Concrete beams strengthened with near surface mounted reinforcement of CFRP" International Conference on FRP Composites in Civil Engineering, Volume 2, J.-G. Teng (Ed). ISBN: 008-043945-4 pp 1059-1066

15. M. Clarin, "Betongbalkar förstärkta med kolfiberkomposit" Master Thesis, Division of Structural Engeineering, Luleå University of Technology, ISSN: 1402, 2022:130 CIV. p 174.

16. H. Nordin, B. Täljsten and A. Carolin, 2001,
"Concrete beams strengthened with prestressed near surface mounted reinforcement (NSMR)" International Conference on FRP Composites in Civil Engineering Volume 2, J.-G. Teng (Ed). ISBN: 0-08-043945-4, (2001), pp 1067-1075.

17. A. Bennitz, (2011), "Externally unbonded posttensioned CFRP tendons: A system solution", Doctoral Thesis, Luleå University of Technology, ISBN: 978-91-7439-206-7, p 198.

18. A. Bennitz, J.W. Schmidt, J. Nilimaa and B. Täljsten, (2012), "Reinforced concrete T-beams externally prestressed with unbonded carbon fibrereinforced polymer tendons", ACI Structural Journal, ISSN 0889-3241, E-ISSN 1944-7361, Vol. 109 , nr 4, s. 521-530.

19. O. Enochsson, 2005, CFRP strengthening of concrete slabs, with and without openings: experiment, analysis, design and field application, Licentiate thesis, 2005:87, ISSN 1407, Luleå University of Technology, 2005, pp 154

20. O. Enochsson, J. Lundqvist, B. Täljsten, P. Rusinowski, T. Olofsson, 2006: "CFRP strengthened openings in two-way concrete slabs An experimental and numerical study". Construction and Building Materials (2006).

21. C. Popescu, G. Sas, T. Blanksvärd and B. Täljsten, 2015, "Concrete walls weakened by openings as compression members - A review", Engineering Structures 89 (2015), p 172-190.

22. C. Popescu, 2017, CFRP Strengthening of Cut-Out Openings in Concrete Walls - Analysis and Laboratory Tests, Doctoral Thesis, ISBN 978-917583-795-6, Luleå University of Technology, pp 165.

23. C. Popescu, G. Sas, T. Blanksvärd and B. Täljsten, (2017), "Concrete walls with cutout openings strengthen by FRP confinement", Journal of composites for construction, ISSN 1090-0268, EISSN 1943-5614, Vol. 21, nr 3.

24. M. Mohammed, "Fatiuge Behaviour of RC Beams Strengthened with CFRP - Analytical and Experimental Investigations", (2015), Doctoral Thesis, Luleå University of Technology, ISBN 97891-7583-235-7, p 276.

25. M. Mohammed, Blanksvärd T. and B. Täljsten, (2016), "A two-scale model for high-cycle fatigue at the fibre-reinforced polymer concrete interface", Computers and Concrete, ISSN 1598-8198, Vol. 116, s. 12-20.

26. A. Carolin, and B. Täljsten, 2005: "Theoretical Study of Strengthening for Increased Shear Bearing Capacity". Journal of Composites for Construction, Volume 9, Issue 6.

27. A. Carolin and B. Täljsten, 2005: "Experimental Study of Strengthening for Increased Shear Bearing Capacity”. Journal of Composites for Construction, 
Volume 9, Issue 6.

28. J.F. Chen, and J. G. Teng, 2003a_. "Shear capacity of fibre-polymer-strengthened reinforced concrete beams: Fibre reinforced polymer rupture." J. Struct. Eng., 129_5_,615-625

29. Consiglio Nazionale delle Ricerche CNR. 2005. "Instructions for design, execution and control of strengthening interventions through fiber-reinforced composites." CNR-DT 200/04, Consiglio Nazionale delle Ricerche, Rome, Italy (in English

30. fib Bulletin 14. 2001. Externally bonded FRP reinforcement for RC structures, $\mathrm{CH}-1015$, Lausanne

31. B. Täljsten, 2006 "FRP strengthening of existing concrete structures." Design guideline, 4th Ed., Luleå University Printing Office, Luleå.

32. G. Sas, B. Täljsten, J. Barros, J. Lima and A. Carolin, 2009: "Are available models reliable for predicting the FRP contribution to the shear resistance of RC beams?", Accepted for publication in Journal of Composites for Construction, 2009.

33. G. Sas, "FRP Shear Strengthening of Reinforced Concrete Beams", (2011), Doctoral Thesis, Luleå University of Technology, ISBN: 978-91-7439-2395, p 248.

34. B. Täljsten, T. Blanksvärd and G. Sas G, 2011, "Handbok för dimensionering och utförande $i$ samband med förstärkning av betongkonstruktioner med pålimmade fiberkompositer, Luleå Tekniska Universitet, Avdelningen för Byggkonstruktion, ISBN 978-91-7439-146-6, p.186 (In Swedish)

35. B. Täljsten, T. Blanksvärd och G. Sas, (2016), "Kompositförstärkning av betong", AB Svensk Byggtjänst, ISBN: 978-91-7333-763-2, p 177.

36. B. Täljsten and T. Blanksvärd, 2007, "MineralBased Bonding of Carbon FRP to Strengthen Concrete Structures", Journal of Composites for Construction, Vol 11, No. 2, March/April 2007, pp120-128

37. D. Becker, 2003, "Concrete slabs strengthened with carbon fiber composites, Master's thesis, Luleå Univ. of Technology, Luleå, Sweden,1402-1617 in Swedish

38. T. Blanksvärd, "Strengthening of concrete structures by the use of mineral-based composites - System and design models for flexure and shear", Doctoral Thesis - Division of Structural Engineering, Luleå University of Technology, ISBN:978-91-86233-235, 2009, p 302.

39. C. Sabau, C. Popescu, G. Sas and T. Blanksvärd, (2017), "Concrete walls with openings strengthened using FRCM composites", Advanced Composites in Construction: Conference Proceedings / [ed] Maurizio Guadagnini \& Sue Keighley, Chesterfield: NetComposites Limited , 2017, s. 188-192

40. B. Täljsten, 2000, "Strengthening of concrete structures with CFRP-sheets Applications and full scale tests in Sweden", ACMBS III MCAPS, Proceedings of the 3rd Conference on Advanced Composite Materials in Bridges and Structures, Ottowa, August 2000, pp 513-520.

41. A. Carolin, 2001, "Strengthening of Concrete Structures with CFRP. Shear strengthening and fullscale applications". Licentiate Thesis 2001:01, Division of Structural Engineering, Luleå University of Technology

42. O. Enochsson, A. Puurula and L. Elfgren, 2004, Beräkning av betongbroars bärförmåga. Interaktion mellan tvärkraft, vridmoment och böjning i Källösundsbron (Assessment of the Load Carrying Capacity of Concrete Bridges. Interaction between torsion, shear and bending in the Källösund Bridge. In Swedish) Technical Report 2004:15, Luleå

43. A. Puurula, 2004, Assessment of Prestressed Concrete Bridges Loaded in Combined Shear, Torsion and Bending. Licentiate Thesis 2004:43, Luleå: Div. of Structural Engineering, Luleå Univ. of Technology, $103+144 \mathrm{pp}$

44. B. Täljsten, 2006, FRP Strengthening of Existing Concrete Structures. Design Guideline. Division of Structural Engineering, Luleå University of Technology, 4th Ed, Luleå 2006, 227 pp, ISBN 9189580-03-6. 